\title{
Optimum Design of Waste Water Treatment Network
}

\author{
Gopal Chandra SAHU \\ Department of Energy Science and Engineering \\ Indian Institute of Technology, Bombay, Powai, Mumbai, 400076, INDIA

\begin{abstract}
Anurag GARG
Centre for Environmental Science and Engineering

Indian Institute of Technology, Bombay, Powai, Mumbai, 400076, INDIA
\end{abstract}

Thokozani MAJOZI

Department of Chemical Engineering

University of Pretoria, Pretoria, SOUTH AFRICA

and

\section{Santanu BANDYOPADHYAY, *}

Department of Energy Science and Engineering

Indian Institute of Technology, Bombay, Powai, Mumbai, 400076, INDIA

*Corresponding author. Tel.:+91-22-25767894; fax +91-22-25726875

E-mail: santanub@iitb.ac.in 


\begin{abstract}
:
Various environmental regulations imply that it is important to minimize the cost associated with treatment of different industrial wastes prior to its discharge to the environment. In this paper an algebraic methodology, based on the principles of process integration, is proposed to target the minimum waste treatment flow rate to satisfy environmentally acceptable discharge limit. In the proposed methodology treatment units with fixed outlet concentrations are considered. It is observed that it is not necessary to maximize the usage of the treatment unit with the minimum specific cost. Hence, a prioritized cost for each treatment unit is devised to select appropriate treatment units that minimize the overall operating cost. Applicability of the proposed methodology is demonstrated through examples.
\end{abstract}

Keywords: Chemical processes; Environment; Mathematical modeling; Optimization; Water; Waste treatment.

\title{
1. Introduction
}

Waste water management has become an important issue for chemical process industries due to environmental rules and regulations to maintain a cleaner environment. The cost of treating waste water is increasing steadily as environmental regulations are becoming more and more stringent. The installations of treatment units require capital expenditure with little or no influence on economic benefits. Principles of process integration, which were first developed for the efficient use of energy, ${ }^{1-3}$ may be applied to address the issues related to waste water 
management in a process industry. Comprehensive waste water management entails two distinct sequential activities: targeting of optimum effluent flow to be treated to meet the environmental norms and secondly to generate the systematic treatment network to satisfy the targeted effluent flow and environmental regulations. In general, treatment units are categorized as: unit with fixed outlet concentration $\left(C_{\text {out }}\right)$ (e.g., filtration), unit with fixed removal ratio (e.g., scrubber), and partitioning treatment units (e.g., membrane separation systems).

Several techniques have been developed to target the minimum effluent requirement to satisfy environmental regulations for waste water networks. Takama et al. ${ }^{4}$ solved the complete water management problem using superstructure-based non-linear optimization technique. Wang and $\mathrm{Smith}^{5}$ have developed a systematic approach for designing distributed effluent treatment systems. This procedure has been extended by Kuo and Smith ${ }^{6}$ for multiple treatment processes. Mathematical optimization techniques have also been used to design distributed effluent treatment systems. ${ }^{7,8}$ Alva-Argáez et al. ${ }^{9,10}$ addressed the entire water management problem through superstructure-based mixed integer non-linear programming. Freitas et al. ${ }^{11}$ proposed the use of the hierarchical design approach, ${ }^{12}$ supplemented with a database and expert system to determine the best sequence of treatment processes. However, such a method cannot guarantee the optimality. Statyukha et al. ${ }^{13}$ proposed a hybrid approach for designing waste water treatment networks. Recently, Tan et al. ${ }^{14}$ and $\mathrm{Ng}$ et al. ${ }^{15}$ have proposed superstructure model and automated targeting, respectively, for synthesizing water networks with partitioning treatment units.

The insight-based techniques are employed to obtain solutions with graphical analysis and/or by algebraic procedures implemented in spread sheets. Zhelev and Bhaw ${ }^{16}$ (2000) introduced combined water and oxygen pinch analysis for designing optimum waste water 
treatment network. The minimum oxygen requirement for waste degradation was targeted in combination with water pinch analysis. Interaction between operations that use water and effluent treatment systems have also been addressed. ${ }^{17-23}$ These techniques are developed for the treatment units without any flow loss. Meanwhile, Bandyopadhyay ${ }^{24}$ proposed a technique to target the optimum effluent treatment to satisfy the environmental regulations considering water loss in the treatment unit. Recently, Liu et al. ${ }^{25}$ proposed a methodology for optimizing the operating cost of the treatment network with only two treatment units.

All the above mentioned techniques are either based on mathematical optimization or conceptual approach. The major drawbacks associated with these mathematical techniques are model formulation and convergence efficiency. It is of utmost importance to develop the generalized superstructure in the mathematical modeling of the problem to embed the global optimal solution. On the other hand, standard optimization packages are used to solve these problems. This leads to inefficient solution procedure as these generalized optimization routines fail to exploit the special structure of these problems. Meanwhile, methodologies based on conceptual approaches, like pinch analysis, help in getting a physical insight of the problem through its graphical representations and simplified tableau-based calculation procedures. However, the complex problems may not be always solvable by these techniques. Note that cost for the treatment network was not optimized by any of the techniques, proposed in the literature. Therefore, the primary objective of this paper is to develop an algebraic technique to optimize the cost for the treatment network. However, the technique is limited to single-contaminant water networks with fixed outlet concentration type treatment units.

\section{Problem Statement}


In a waste water network all the waste generating sources $\left(S_{i}\right.$, represents $i^{\text {th }}$ source) can be characterized by their discharge flow $\left(F_{s i}\right)$ and concentration level $\left(C_{s i}\right)$. Let there are $N W$ number of waste generating sources. Usually the concentration levels of waste generating sources, discharged from most of the industries, are significant enough to damage the environment. Hence, environmental regulations are imposed on the overall plant to discharge waste to the environment below some prescribed concentration level. Let $C_{e}$ denotes the concentration level below which waste may be discharged to the environment. Hence, these waste streams have to be treated and impurity has to be removed in the treatment plant. In the treatment plant, $n$ number of fixed $C_{\text {out }}$ type treatment units $\left(T_{i}\right.$, represents $i^{\text {th }}$ treatment unit) with different outlet concentration $\left(C_{\text {outi }}\right)$ and specific operating cost $\left(U_{T i}\right)$ are given. It may be noted that operating cost of a treatment unit may be non-linear function of effluent flow rate and other design parameters. However, in this paper, the operating cost of a treatment unit is assumed to be proportional to the effluent flow rate it handles. ${ }^{5,6,24}$ The objective is to minimize the total operating cost of the treatment plant.

The superstructure of the problem is shown as Figure 1. From Figure 1 it can be observed that flow from any source may be treated with any combination of existing treatment units or may be by-passed. It can also be analyzed that treated flow from treatment units can be re-treated with other treatment units for achieving the optimum operating cost. After treatment, the exit streams from the treatment units can be mixed with the by-pass streams and thrown to the environment such that the overall concentration should be less than $C_{e}$. The objective is to develop a mathematically rigorous algorithmic technique, with graphical representation, to target the effluent flow rate to be treated in the treatment plant such that the overall operating cost of 
the treatment plant is minimized while satisfying the prescribed concentration limit, imposed by environmental regulations. Mathematical formulation of the superstructure is described below.

Let $f_{i j}$ represents the flow transferred from source $S_{i}$ to treatment unit $T_{j}$ and $f_{i b}$ represents the flow bypassed from source $S_{i}$ without being treated. Similarly, $f_{T i j}$ represents the flow transferred from exit of treatment unit $T_{i}$ to treatment unit $T_{j}$ for retreatment and $f_{\text {Tie }}$ represents the flow that is discharged directly to the environment. Due to the flow conservation, the flow balance for every internal waste generating source may be written as:

$$
\sum_{j=1}^{n} f_{i j}+f_{i b}=F_{s i} \quad \forall i \in\{1,2, \ldots, N W\}
$$

Flow balance for each treatment unit can be written as (see Figure 1):

$$
\sum_{i=1}^{n} f_{T j i}+f_{T j e}=\sum_{i=1}^{N W} f_{i j}+\sum_{i=1}^{n} f_{T i j} \quad \forall j \in\{1,2, \ldots, n\}
$$

Environmental discharge limit $\left(C_{e}\right)$ may be mathematically expressed as:

$$
\sum_{i=1}^{N W} f_{i b} C_{s i}+\sum_{j=1}^{n} f_{\text {Tje }} C_{o u t j} \leq \sum_{i=1}^{N W} F_{s i} C_{e}
$$

Note that all the flow variables are non-negative. As the concentration levels for every source as well as the outlet concentration of each treatment unit are known by definition, equation (3) is 
linear in terms of flow variables. The objective function is to minimize the overall operating cost $(\psi)$ of the treatment network:

$$
\psi=\sum_{j=1}^{n}\left(\sum_{i=1}^{N W} f_{i j}+\sum_{i=1}^{n} f_{T i j}\right) U_{T j}
$$

The objective is to minimize $\psi$ subject to the constraints given by equations (1)-(3). As all the constraints as well as the objective function are linear, the optimization problem is a linear programming (LP) problem. There are $(n+1)(n+N W)$ flow variables, $(n+N W)$ equality constraints and one inequality constraint. Therefore, the degree of freedom for this optimization problem is $n(n+N W)$. The above LP problem can be solved using mathematical optimization techniques.

It may be noted that the minimization of operating cost for waste water treatment network is a special network flow optimization problem. Network flow optimization problems can be solved by special algorithms based on their special structures. A detailed review of different network flow problems and associated special algorithms are outlined by Ahuja et al. ${ }^{26}$. However, network flow problems can also be solved using conventional simplex algorithm of linear programming. It is observed that special structures of these problems and/or special algorithms associated with a particular type of problems help in solving these problems in an efficient and faster way. Hence, the objective is to develop mathematical rigorous algebraic algorithms to solve the above problem. An algebraic algorithm is proposed in this paper to solve this linear programming problem. Before illustrating the proposed algorithm, related 
mathematical results, based on special structures of the problem, are discussed in the following section.

\section{Targeting minimum effluent flow rate for single treatment unit}

Bandyopadhyay et al. ${ }^{20}$ and Bandyopadhyay ${ }^{24}$ have proposed a novel limiting composite curve, called the waste composite curve (WCC), to target the minimum effluent to be treated to meet environmental norms. It may be noted that the wastewater composite curve is equivalent to the original source composite curve ${ }^{20}$ without any internal demand. Waste composite curve is the plot of concentration $\left(C_{k}\right)$ versus cumulative contaminant load $\left(M_{k}\right)$. The cumulative contaminant load, used for WCC of a waste water network at a concentration $\left(C_{k}\right)$, can be expressed as follows ${ }^{24}$ :

$$
M_{k}=\left\{\begin{array}{lr}
0 & k=1 \\
\sum_{l=1}^{k-1} F_{l}\left(C_{l}-C_{k}\right) & \forall C_{l}>C_{k}, k>1
\end{array}\right.
$$

It may be noted that $F_{l}$ denotes the flow at the concentration level $C_{l}$. A typical waste composite curve is shown in Figure 2. It may be noted that the waste composite curve may be generated before designing the waste treatment network. On simplification of equation (5) for last concentration level (i.e., $C_{k}=0$ ) the total contaminant load $\left(M_{T}\right)$ thrown to the environment, before treatment, can be determined. 


$$
M_{T}=\sum_{l=1}^{n} F_{l} C_{l}
$$

After generating the waste composite curve for given waste water flows, the next step is to determine the minimum effluent treatment required to satisfy the environmental regulation $\left(C_{e}\right)$. It can be noted that there may be few waste sources having concentrations below to $C_{e}$. These sources may be by-passed any treatment unit. On the other hand, the sources with concentration higher than $C_{e}$ need to be treated fully or partially through the treatment unit network. After treatment, the treated water from the treatment unit network can be mixed directly with the bypassed flows to produce the final dischargeable waste water, satisfying the environmental norm of $C_{e}$. As effective concentration of sources below to $C_{e}$ is less then $C_{e}$, the aggregate concentration of treated and by-passed sources above to $C_{e}$ may be greater than $C_{e}$. Let $C_{e}^{\prime}$ be the aggregate concentration of mixed flow of all treated and by-passed sources above to $C_{e}$. To satisfy the environmental discharge limit $\left(C_{e}\right)$, the following mass balance has to be satisfied.

$$
\sum_{\substack{l=1 \\ C_{l}>C_{e}}}^{N W} F_{l} C_{e}^{\prime}+\sum_{\substack{l=1 \\ C_{l} \leq C_{e}}}^{N W} F_{l} C_{l}=\sum_{l=1}^{N W} F_{l} C_{e}
$$

By simplifying the above equation the aggregate discharge limit from the treatment plant $\left(C_{e}^{\prime}\right)$ can be determined as: 


$$
C_{e}^{\prime}=\frac{\sum_{\substack{l=1 \\ C_{l}>C_{e}}}^{N W} F_{l} C_{l}+\sum_{\substack{l=1 \\ C_{l} \leq C_{e}}}^{N W} F_{l}\left(C_{e}-C_{l}\right)}{\sum_{\substack{l=1 \\ C_{l}>C_{e}}}^{N W} F_{l}}
$$

The waste sources above $C_{e}^{\prime}$ have to be treated and the contaminant load has to be removed in the effluent treatment plant to satisfy the aggregate discharge limit from the treatment plant $\left(C_{e}^{\prime}\right)$. From equation (8), it can be observed that $C_{e}^{\prime} \geq C_{e}$. Hence, before discharge to the environment, these treated wastes have to be added with the sources with concentration lower then $C_{e}$. This can be expressed geometrically with Figure 2. Draw a vertical line on the concentration vs contaminant load diagram that meets the waste composite curve at $C_{e}^{\prime}$. The vertical line divides the waste composite curve and, hence, the total contaminant load into two parts. Let us denote the contaminant load left of the vertical line as $\Delta M_{T e f}$ and the contaminant load right of the vertical line as $\Delta M_{s}$. If the total waste water is treated with a contaminant load of $\Delta M_{T e f}$, the concentration of the waste water has to be $C_{e}$ (Based on equations 7 and 8). Therefore, the contaminant load right of the vertical line $\left(\Delta M_{s}\right)$ can be discharged safely to the environment, and the remaining load $\left(\Delta M_{T e f}\right)$ has to be treated. Thus, $\Delta M_{T e f}$ amount of load has to be removed from the system to satisfy environmental regulations (see Figure 2). Let $C_{\text {out }}$ be the fixed outlet concentration of a treatment unit. According to the definition of fixed $C_{o u t}$ treatment unit, any treatment line, i.e., the line that represents the removal of contaminant load on a concentration (C) vs contaminant load $(M)$ diagram must pass through the point for $C_{\text {out }}$. The equation of the treatment line is given as: 


$$
f_{T}=\frac{\Delta M_{T e f}-M}{C-C_{\text {out }}}
$$

where $C$ denotes the concentration corresponding to the mass load, $M$, on the treatment line and $f_{T}$ denotes the corresponding treatment flow. At the intersection point of treatment line and the concentration axis, $M$ is zero and $C$ represents the concentration of the effluent stream entered to the treatment unit (see Figure 2). From the above equation it can be observed that the treatment flow rate can be minimized by maximizing the concentration of effluent stream. Therefore, to minimize the treatment flow, the treatment line should be rotated upwards with $\left(\Delta M_{T e f}, C_{o u t}\right)$ as the pivot point (see Figure 2). It should be noted that at any concentration level, the treatment line cannot pickup more contaminant load than what is available (as given by the waste composite curve). Therefore, the minimum treatment flow can be targeted by rotating the treatment line with $\left(\Delta M_{T e f}, C_{\text {out }}\right)$ as the pivot point such that it just touches the waste composite curve (Figure 2). Based on this, the following equation is developed for targeting the minimum effluent treatment flow rate $\left(f_{T}\right)$ :

$$
f_{T}=\max _{k}\left(\frac{\Delta M_{T_{e f}}-M_{k}}{C_{k}-C_{\text {out }}}\right)
$$

The concentration level for which the treatment line touches the waste composite curve, denotes the treatment pinch concentration $\left(C_{p}\right)$. In the absence of any other treatment unit, equation (10) represents the target for the minimum effluent treatment flow rate requirement and, hence, corresponds to the minimum operating cost. However, this may not be true if multiple treatment units, with different specific operating cost, are available. 


\section{Targeting multiple treatment units for minimum operating cost}

Before illustrating the targeting technique, related mathematical results are proved rigorously in the following section.

\subsection{Mathematical results}

From Figure 2, it can be observed that any treatment unit $\left(T_{k}\right)$ below $C_{e}^{\prime}\left(C_{\text {outk }} \leq C_{e}^{\prime}\right)$ is able to remove the contaminant load $\Delta M_{T e f}$. However, lower the outlet concentration of treatment unit lower the treatment flow requirement (equation 10). Let $T_{j}$ be the treatment unit for which outlet concentration is the least (i.e., $C_{\text {out }}<C_{\text {outk }}$ for each $k$ ). Let $f_{T j}$ be the treatment flow requirement

for the $j^{\text {th }}$ treatment unit, which is least possible treatment flow for the plant. As $f_{T j}$ is a feasible treatment flow to remove $\Delta M_{T e f}$ contaminant load, $f_{T j} U_{T j}$ is the operating cost $\left(\Psi_{T j}\right)$ for the treatment unit $T_{j}$.

$$
\Psi_{T j}=U_{T j} f_{T j}
$$

Note that $U_{T j}$ is the unit operating cost for treatment unit $T_{j}$. However, it may be possible that combination of the treatment units can produce a feasible solution along with treatment unit $T_{j}$ with reduced operating cost. Hence, the objective is to introduce which treatment unit along with $T_{j}$ such that the operating cost can be minimized further. 
Let the treatment pinch obtained be $C_{p j}$ while solving for the treatment unit $T_{j}$. If another treatment unit $\left(T_{i}\right)$ with an outlet concentration $C_{\text {outi }}$ and operating cost of $U_{T i}$ is introduced, then the treatment flow required for $T_{j}$ and the overall operating cost may be further reduced. Introduction of another treatment unit $\left(T_{i}\right)$ creates another treatment line from $C_{\text {out }}$ with the same treatment flow added to the original treatment line. Hence, the initial part of the treatment line may be plotted using equation (9) in the interval $\left(C_{\text {out }}, C_{\text {out }}\right]$ as the effluent treatment flow requirement corresponds to the treatment unit $T_{j}$. If $C_{\text {out }} \geq C_{p j}$, then based on equation (10) the effluent flow target corresponding to the treatment unit $T_{j}$ will remain same as $f_{T j}$. Hence, there is no reduction of effluent treatment for $T_{j}$ but increment in treatment flow for $T_{i}$, which causes an additional cost to the overall plant. This proves the following result:

Lemma 1: Introduction of a treatment unit with outlet concentration greater than the treatment pinch concentration, produced by the treatment unit with least outlet concentration, leads to sub-optimal results.

Lemma 1 suggests that the overall operating cost may be reduced by introducing a treatment unit with outlet concentration less then $C_{p j}$.

Without loss of generality, it may be assumed that another treatment unit $\left(T_{i}\right)$ is available with the outlet concentration $C_{o u t i}$ such that $C_{p j}>C_{o u t i}>C_{o u t j}$. Assume that the treatment flow requirement for $T_{j}$ is reduced by $\delta f_{T}$. To take care of the treatment flow requirement, treatment unit, $T_{i}$, is introduced at $C_{\text {out }}$ as shown in the composite treatment line in Figure 3. Then, from Figure 3 the minimum requirement of the treatment flow $\left(f_{T_{i}}\right)$ for the treatment unit $T_{i}$ (equation 
12 ) and the corresponding operating cost $\left(\Psi_{T_{j i}}\right)$ (equation 13) can be determined. Note that flow corresponds to composite treatment line, below $C_{o u t i}$, is the cumulative treated flow for $T_{i}$ and $T_{j}$.

$$
\begin{aligned}
& f_{T i}=\frac{f_{T j}\left(C_{p j}-C_{o u t j}\right)-\left(f_{T j}-\delta f_{T}\right)\left(C_{o u t i}-C_{o u t j}\right)}{C_{p j}-C_{o u t i}}-\left(f_{T j}-\delta f_{T}\right)=\delta f_{T}\left(\frac{C_{p j}-C_{o u t j}}{C_{p j}-C_{o u t i}}\right) \\
& \boldsymbol{\psi}_{T j i}=U_{T j}\left(f_{T j}-\delta f_{T}\right)+U_{T i} f_{T i}
\end{aligned}
$$

The introduction of the second treatment unit is advantageous if and only if $\Psi_{T j i}<\Psi_{T j}$. Using equations (11)-(13), this condition may be expressed as:

$$
\frac{U_{T i}}{C_{p j}-C_{o u t i}}<\frac{U_{T j}}{C_{p j}-C_{o u t j}}
$$

The quantity $\left(U_{T i} /\left(C_{p j}-C_{o u t i}\right)\right)$ may be called the prioritized cost of the $i^{\text {th }}$ treatment unit. Most importantly, equation (14) signifies that the introduction of the $i^{\text {th }}$ treatment unit is beneficial only if its prioritized cost is less than that of all other treatment units. It may be noted that similar concept of prioritized cost for multiple resources has been developed by Shenoy and Bandyopadhyay. ${ }^{27}$

It may be noted from equation (14) that the prioritized cost depends on the treatment pinch concentration. Hence it is very much important to study the treatment pinch while introducing other treatment units. For examining, treatment units $T_{j}$ and $T_{i}$ with outlet concentrations $C_{o u t j}$ and $C_{\text {outi }}\left(C_{\text {outj }}<C_{\text {outi }}\right)$, respectively are considered. Treatment flow corresponding to each concentration $\left(C_{k}\right)$ for $T_{j}\left(f_{T j, k}\right)$ as well as for $T_{i}\left(f_{T, k}\right)$ can be determined using equation (9). Let 
$C_{p j}$ and $f_{T j, p}$ be the treatment pinch and the minimum effluent treatment flow requirement for $T_{j}$, respectively. According to equation (10) the following relation can be determined.

$$
f_{T j, p}>f_{T j, k} \quad \text { for each } C_{k}
$$

Using equation (9) the relation between $f_{T j, k}$ and $f_{T i, k}$ can be expressed as:

$$
f_{T i, k}=f_{T j, k}\left(\frac{C_{k}-C_{o u t j}}{C_{k}-C_{o u t i}}\right)
$$

Therefore, change in treatment flow requirement at each concentration $\left(f_{T i, k}-f_{T j, k}\right)$ can be expressed as:

$$
\Delta f_{T, k}=f_{T j, k}\left(\frac{C_{\text {outi }}-C_{\text {outj }}}{C_{k}-C_{\text {outi }}}\right)
$$

Pinch change is only possible when $\Delta f_{T, k}$ for some $k$ is greater than $\Delta f_{T, p}$. Equation (18) may be used to determine the relation between $\Delta f_{T, k}$ and $\Delta f_{T, p}$.

$$
\Delta f_{T, p}-\Delta f_{T, k}=\left(\frac{C_{\text {outi }}-C_{\text {out }}}{C_{p j}-C_{\text {outi }}}\right)\left[f_{T j, p}-f_{T j, k}\left(\frac{C_{p j}-C_{\text {outi }}}{C_{k}-C_{\text {outi }}}\right)\right]
$$

From equations (15) and (18), it may be observed that $\Delta f_{T, p}>\Delta f_{T, k}$ when $C_{k}>C_{p j}$. Otherwise, there is a possibility for $\Delta f_{T, p} \leq \Delta f_{T, k}$. This implies the following result: 
Lemma 2: Introduction of a treatment unit with higher outlet concentration may lead to jump the treatment pinch to a lower concentration.

As discussed earlier the treatment unit with only higher outlet concentration may be required to introduce for minimizing the overall operating cost. Hence, according to Lemma 2 treatment pinch point may jump below for this scenario. As the treatment pinch may be changed due to introduction of $T_{i}$, the prioritization cost with respect to the revised treatment pinch may not follow the same order. Hence, it is important to analyze how the order of prioritization is going to change due to the new treatment pinch. Let's consider that the prioritized cost for $i^{\text {th }}$ treatment unit, $T_{i},\left(P C\left(T_{i}\right)\right)$ is lower than that for other treatment units. Using equation (14), prioritization cost relation of $i^{\text {th }}$ treatment unit with other treatment units below the treatment pinch can be expressed as:

$$
\frac{U_{T i}}{C_{p j}-C_{\text {outi }}}<\frac{U_{T k}}{C_{p j}-C_{\text {out } k}} \quad \forall i \neq k \text { and } C_{\text {outit }}, C_{\text {out }}<C_{p j}
$$

As discussed earlier the first prioritization will be carried out by $C_{p j}$ which is generated by the treatment unit $T_{j}$ with outlet concentration $C_{o u t j}$. For further reduction of operating cost $i^{\text {th }}$ treatment is introduced. According to Lemma 2 the treatment pinch might jump to a lower concentration. Let $C_{p i}$ be the new revised treatment pinch because of the introduction of $i^{\text {th }}$ treatment unit. Therefore, $C_{p i}<C_{p j}$ (according to Lemma 2). Due to the revised treatment pinch, the revised prioritized cost $\left(R P C\left(T_{k}\right)\right)$ for any treatment unit, $T_{k}$, can be represented as: 


$$
\operatorname{RPC}\left(T_{k}\right)=\frac{U_{T k}}{C_{p i}-C_{\text {outk }}}
$$

As suggested through equation (19), $T_{i}$ is the cheapest prioritized cost based on the treatment pinch $C_{p j}$. Due to change of pinch; the prioritized cost for each treatment unit can be changed. For analyzing this, the relation between $R P C\left(T_{i}\right)$ and $R P C\left(T_{k}\right)$ for any $k$ is determined in equation (21). Note that equation (21) can be derived using equations (19) and (20) through simple algebraic manipulation (not included due to brevity).

$$
R P C\left(T_{i}\right)-R P C\left(T_{k}\right)<\frac{R P C\left(T_{i}\right) R P C\left(T_{k}\right)\left(C_{p j}-C_{p i}\right)}{U_{T i} U_{T k}}\left(U_{T k}-U_{T i}\right)
$$

Based on equations $(19-21)$ and the relation $C_{p i}<C_{p j}$, remark on reordering of revised prioritization cost can be derived as shown in Table 1 . These observations lead to the following result:

Lemma 3: Order of revised prioritized cost for treatment units with outlet concentration only lies in the interval $\left[C_{\text {outj }}, C_{\text {outi }}\right]$ can be changed.

According to Lemma 3, revised prioritized cost for the treatment unit $T_{i}$ may or may not be cheapest further. Hence, to satisfy our objective the treatment unit $T_{i}$ can be utilized up to a point until it is cheap based on prioritization or by revised prioritization cost. So, it is required to analyze how the treatment line for the treatment unit $T_{i}$ behaves for the following cases; 
(i) Treatment pinch changed and $T_{i}$ is no longer cheapest based on revised prioritization,

(ii) Treatment pinch changed and $T_{i}$ still remain the cheapest.

Any treatment unit can be utilized up to a point where it remains the cheapest. Hence, in case (i), the treatment line should not leave the first treatment pinch as it is cheapest based on it. Therefore, at maximum utilization the treatment line will touch the composite curve at both the

treatment pinch points, $C_{p j}$ and $C_{p i}$. However, at $C_{o u t i}$ the treatment line may be away from the composite curve.

Theorem 1: Maximize the use of the treatment unit with least prioritized cost leads to minimize the overall operating cost of the treatment plant.

Based on the above mathematical results an algebraic algorithm is derived.

\subsection{Algorithm for targeting of multiple treatment units}

After arranging treatment units in terms of increasing outlet concentrations, the prioritized cost for each treatment unit identifies the order in which treatment units have to be targeted. The following steps may be performed to target the treatment units in cost effective way. 
Step 1: Determine $C_{e}^{\prime}$ using equation (8).

Step 2: Determine cumulative contaminant load at each concentration using equation (5). Note that flow at outlet concentrations of treatment units as well as $C_{e}^{\prime}$ can be taken as zero while determining the cumulative contaminant load.

Step 3: Determine $\Delta M_{\text {tef }}$ as the cumulative contaminant load corresponding to $C_{e}^{\prime}$.

Step 4: Determine the treatment unit below $C_{e}^{\prime}$ having least outlet concentration. Let $T_{j}$ be the treatment unit having least outlet concentration. Determine minimum effluent treatment flow requirement for $T_{j}$ and treatment pinch $\left(M_{p j}, C_{p j}\right)$. Note that minimum effluent treatment can be targeted using equation (10).

Step 5: Determine the prioritization cost for each treatment unit using equation (14). For minimum operating cost, the acceptable treatment units will form a sequence such that their outlet concentrations are in increasing order while their prioritized costs are in decreasing order. This is because a treatment unit with higher prioritized cost can only be used if its $C_{\text {out }}$ limit is lower.

Step 6: The effluent treatment flow corresponding to the $k^{\text {th }}$ targeted treatment unit $\left(f_{t k}\right)$ may be calculated from

$$
f_{\text {tk }}= \begin{cases}\max _{l}\left(\frac{M_{\text {coutk }}-M_{l}}{C_{l}-C_{\text {outk }}}\right) & \text { for } C_{\text {outk }+1} \geq C_{l}>C_{\text {outk }} \geq C_{e}^{\prime} \\ \max _{l}\left(\frac{\Delta M_{\text {Tef }}-M_{l}}{C_{l}-C_{\text {outk }}}\right) & \text { for } C_{\text {out }+1} \geq C_{l}>C_{e}^{\prime}>C_{\text {outk }}\end{cases}
$$


Denote $\left(M_{l}, C_{l}\right)$, for which $f_{t k}$ is maximum, as $\left(M_{f k}, C_{f k}\right)$. As discussed earlier, the treatment pinch may jump to a lower concentration while solving for the $k^{\text {th }}$ treatment unit. If treatment pinch does not change go to step 13. Else, go to step 7.

Step 7: Let the revised pinch point be $\left(M_{p k}, C_{p k}\right)$. Determine revised prioritization cost for the treatment units with the revised pinch point. If $k^{\text {th }}$ treatment unit is still cheaper then go to step 13. Else go to step 8 .

Step 8: Find a new pinch point $\left(M_{p k r}, C_{p k r}\right)$ using equation 10 , by replacing $\left(\Delta M_{T e f}, C_{o u t}\right)$ by $\left(M_{p k}\right.$, $\left.C_{p k}\right)$ in the interval $\left[C_{p j}, C_{p k}\right)$.

Step 9: Determine revised prioritized cost based on $C_{p k r}$. If $k^{\text {th }}$ treatment unit is still not cheapest then go to step 8 and replace $\left(M_{p k}, C_{p k}\right)$ by $\left(M_{p k r}, C_{p k r}\right)$. Else, go to step 10 .

Step 10: As the treatment line should touch the composite curve at both the treatment pinch points $\left(M_{p k}, C_{p k}\right)$ and $\left(M_{p k r}, C_{p k r}\right)$ and also need to pass through $C_{o u t k}$, the maximum utilizable point, $M_{k, \max }$, for $k^{\text {th }}$ treatment unit can be determined using equation (24).

$$
M_{k \max }=M_{p k}+\left(C_{o u t k}-C_{p k}\right)\left(\frac{M_{p k r}-M_{p k}}{C_{p k r}-C_{p k}}\right)
$$

Note that equation (24) can be derived using equation of a straight line.

Step 11: Determine revised $f_{t k}$ and $f_{t k-1}$ as per equations (25) and (26), respectively.

$$
\begin{aligned}
& f_{t k}=\frac{M_{k \max }-M_{p k}}{C_{p k}-C_{\text {outk }}} \\
& f_{t k-1}=\frac{M_{k-1}-M_{k \max }}{C_{\text {outk }}-C_{\text {out } k-1}}
\end{aligned}
$$


Note that $M_{f k-1}$ and $M_{f k}$ will be revised as $M_{k m a x}$ and $M_{p k}$, respectively.

Step 12: Repeat steps 5 to 11 for the treatment units lies in the interval $\left(C_{\text {outk }}, C_{p k}\right)$.

Step 13: Using equation (27) the flow that needs to be treated in the $k^{\text {th }}$ prioritized treatment unit can be determined.

$$
F_{T k}= \begin{cases}f_{t k} & \text { for } k=1 \\ f_{t k}-f_{t k-1} & \text { for } k>1\end{cases}
$$

Step 14: If $F_{T k}$ is negative for some $k$, then revise $f_{t k}$ and $f_{t k-1}$ as follows and go to step 13 for determining revised $F_{T k}$ and $F_{T k-1}$. Else, go to step 15 for determining minimum treatment operating cost.

$$
f_{t k}=f_{t k-1}=\frac{M_{f k-2}-M_{f k}}{C_{f k}-C_{f k-2}}
$$

Step 15: Determine the sum of product of treated flow in the treatment units with their corresponding cost as the optimized operating cost for the treatment network.

\section{Illustrative Examples}

In this section different illustrative examples are considered to demonstrate the applicability of the proposed methodology. 


\subsection{Example 1: Total water network}

Limiting process data for this example are given in Table $2 .{ }^{20}$ Freshwater concentration is $0 \mathrm{ppm}$. The environmental limit is assumed to be $70 \mathrm{ppm}$ instead of $20 \mathrm{ppm}^{20}$ Three treatment units are considered to remove the contaminant load from the plant. Furthermore, it has been assumed that the treated water cannot be recycled across the water-using processes. Bandyopadhyay et al. ${ }^{20}$ have targeted the minimum requirement of $200 \mathrm{t} / \mathrm{h}$ of fresh water and $120 \mathrm{t} / \mathrm{h}$ of waste water generation. Corresponding fresh water pinch is determined to be $180 \mathrm{ppm}$. In this example, waste water is generated at two concentration levels: $85 \mathrm{t} / \mathrm{h}$ of waste water is generated at $250 \mathrm{ppm}$ and $35 \mathrm{t} / \mathrm{h}$ of waste water is generated at $180 \mathrm{ppm}$.

Based on these two waste generating sources, effluent treatment flow requirement corresponding to different treatment units are determined. As there is no waste generation below the environmental discharge limit $(70 \mathrm{ppm})$, the treatment discharge limit $\left(C_{e}^{\prime}\right)$ and environmental discharge limit $\left(C_{e}\right)$ are identical (step 1). Based on step 2, concentrations of all waste sources, environmental discharge limit and outlet concentrations of all treatment units are tabulated in decreasing order in the first column of Table 3. Cumulative contaminant load (using equation (5)), corresponding to each concentration in column one, is tabulated in the second column of Table 3. Figure 4 shows the waste composite curve for this example. From Figure 4 $\Delta M_{T e f}$ can be determined as $19150 \mathrm{~g} / \mathrm{h}$. Note that the cumulative contaminant load (determined in second column of Table 3) corresponding to the treatment discharge limit $\left(C_{e}^{\prime}\right)$ is $\Delta M_{T e f}$. Hence, $\Delta M_{T e f}$ can also be determined directly from Table 3 (step 3). As the treatment unit $T_{1}$ has least outlet concentration, based on step 4 of the proposed algorithm effluent treatment flow requirement for the treatment unit $T_{1}$ and pinch point are determined as $83.26 \mathrm{t} / \mathrm{h}$ (third column 
of Table 3$)$ and $(250,0)$, respectively. Based on the first treatment pinch concentration, $250 \mathrm{ppm}$, prioritized cost for each treatment unit is determined using step 5 of proposed algorithm (see column 4 of Table 4). From column 2 and column 4 of Table 4 it can be observed that, treatment units $T_{3}, T_{2}$ and $T_{1}$ are making a sequence such that their outlet concentrations are in increasing order while their prioritized costs are in decreasing order. Based on step 6, flow for $T_{1}$ can be calculated as 0 , as there is no source below to $70 \mathrm{ppm}$ (equation (23)). While solving flow for $T_{2}$, it can be observed that pinch concentration is changed to $180 \mathrm{ppm}$ (fourth column of Table 3) and the corresponding new pinch point becomes $(5950,180)$. Based on the revised pinch the revised prioritization cost for each treatment unit is determined and tabulated in fifth column of Table 4. It can be observed that $T_{2}$ is not cheapest. Since, $T_{2}$ is not the cheapest based on the revised pinch point, steps 8 and 9 should be carried out with the new pinch point $(5950,180)$. Using equation (10) another pinch point can be determined as $(0,250)$ (see $5^{\text {th }}$ column of Table 3). According to step 9 revised prioritization cost with respective revised pinch point ( $250 \mathrm{ppm})$ need to be determined. As $T_{2}$ is cheapest (see column 2 of Table 4), maximum utilizable point for treatment unit $T_{2}$ can be determined as $17850 \mathrm{~g} / \mathrm{h}$ using step 10. Based on step 11, first and second targeted treatment flows, $f_{t 1}$ and $f_{t 2}$, can be determined as $65 \mathrm{t} / \mathrm{h}$ and $85 \mathrm{t} / \mathrm{h}$, respectively. It may be noted that treatment unit $T_{3}$ lies in the interval $(40,180)$. Based on step 12, flow for $T_{2}$ and $T_{3}$ need to be determined by repeating steps 5 to 11 . From fifth column of Table 4 it can be observed that $T_{3}$ is cheapest. As pinch point is not changed while using $T_{3}$, revised $f_{t 2}$ and $f_{t 3}$ can be determined using equation (23) as $-2.5 \mathrm{t} / \mathrm{h}$ and $120 \mathrm{t} / \mathrm{h}$, respectively. Using equation (27), effluent treatment flow to be treated in first, second and third targeted treatment units, $F_{T 1}, F_{T 2}$ and $F_{T 3}$, can be determined as $65 \mathrm{t} / \mathrm{h},-67.5 \mathrm{t} / \mathrm{h}$ and $122.5 \mathrm{t} / \mathrm{h}$, respectively. It can be observed that $F_{T 2}$ is negative. Hence, using equation (28) revised $f_{t 1}$ and $f_{t 2}$ can be determined as $20 \mathrm{t} / \mathrm{h}$. Using 
equation (27) of step 13, treatment flow for $T_{3}$ and $T_{1}$ treatment units can be determined as 100 $\mathrm{t} / \mathrm{h}$ and $20 \mathrm{t} / \mathrm{h}$, respectively. Hence, based on step 15 the total operating cost for the given network is $300 \$ / \mathrm{h}$. It may be noted that the targeted results are identical with the solved results by mathematical optimization techniques.

Revised composite treatment line is shown in Figure 4. From figure 4 it can be observed that composite treatment line generated by treatment units $T_{3}$ and $T_{1}$ is able to remove $\Delta M_{T e f}$ of mass load. From Figure 4 it can be observed that mass loads from higher concentrations can be removed by treatment unit with higher concentration and the remaining mass load can be removed by treatment units with lower outlet concentration. Based on this observation flow from a high concentration source to selected higher outlet concentration treatment unit can be allocated, up to targeted flow, to design a optimum network. Note that there may be several optimum allocation networks possible. The treatment network for this example is shown in Table 5. It may be noted that Table 5 is shown as matching matrix representation. ${ }^{28}$

On an analogy, the developed methodologies can be applied to various waste treatment problems. To illustrate this, an example related to the reduction of emissions of volatile organic compounds is considered.

\subsection{Example 2: Reduction of emissions of volatile organic compounds}

This example is related to the reduction of emissions of volatile organic compounds (VOCs). VOCs are responsible for producing urban smog in the atmosphere. VOCs are emitted from different sources in a process plant: condenser vents, purges, dryers, combustion processes, 
spillages, tank loading, fugitive emissions from gaskets, shaft seals, sewers, etc. Significant reductions in VOC emissions can usually be achieved by controlling tank venting, condensers and purges and by thorough inspection and maintenance of gaskets and shaft seals. Methods such as condensation, membranes, absorption and adsorption are generally adopted to recover VOC from different source streams. After minimizing VOC emissions from different sources, different recovery processes may be implemented. Recovery, allocation and recycle/reuse of the VOC not only reduce environmental pollution, but also provide significant economic and environmental benefits to the process. Parthasarathy and El-Halwagi ${ }^{29}$ presented optimum mass integration strategies for the maximum VOC recovery. After recovery, different treatment units must be considered for reduction in VOC emission. For treatment and reduction in VOCs, incineration in flares, thermal incinerators, catalytic incinerators, biological scrubbers, etc. may be employed. In this example, the minimum VOC laden stream flow rate to be treated in the treatment unit is determined to achieve the environmental norm.

Process data for this example are given in Table $6 .{ }^{24}$ Note that for illustration purpose the environmental discharge limit is considered as $300 \mathrm{mg} / \mathrm{m}^{3}$ instead of $80 \mathrm{mg} / \mathrm{m}^{3}$ considered by Bandyopadhyay. ${ }^{24}$ Secondly, five treatment units with different outlet concentration and specific operating cost are assumed. The objective is to target the amount of effluent to be treated with minimum operating cost while satisfying the environmental discharge limit of $300 \mathrm{mg} / \mathrm{m}^{3}$. The steps of the proposed algorithm are shown in Tables 7 and 8 . First, the aggregate discharge limit from the treatment plant, $C_{e}^{\prime}$, is determined as $336.08 \mathrm{mg} / \mathrm{m}^{3}$ (equation (8)). Based on step 2, concentrations of all VOCs and cumulative contaminant load (using equation (5)) are tabulated in the first and second columns of Table 7, respectively. Figure 5 shows the waste composite curve for this example. From Figure 5 and Table 7, $\Delta M_{\text {Tef }}$ can be determined as $10540 \mathrm{mg} / \mathrm{s}$. It 
may be noted that $T_{1}$ has least outlet concentration. Hence, based on step 3 of the proposed algorithm effluent treatment flow requirement for the treatment unit $T_{1}$ and pinch point $\left(M_{p 1}\right.$, $\left.C_{p 1}\right)$ are determined as $6.5 \mathrm{~m}^{3} / \mathrm{s}$ (third column of Table 7) and $(1250,1500)$, respectively. Based on the treatment pinch concentration, $1500 \mathrm{mg} / \mathrm{m}^{3}$, prioritized cost for each treatment unit can be determined using equation (14) (see column 4 of Table 8). From column 4 of Table 8 it can be observed that, treatment units $T_{2}, T_{4}$ and $T_{5}$ are making sequence such that their outlet concentrations are in increasing order while their prioritized costs are in decreasing order. Using equation (23) of step 6 of proposed algorithm flow for first and second targeted treatment flows, $f_{t 1}$ and $f_{t 2}$, corresponding to treatment units $T_{2}$ and $T_{4}$ are determined as 0.54 and $9.7 \mathrm{~m}^{3} / \mathrm{s}$. However, from column 5 of Table 7, it can be observed that pinch is jumped from $1500 \mathrm{mg} / \mathrm{m}^{3}$ to $500 \mathrm{mg} / \mathrm{m}^{3}$. Based on $500 \mathrm{mg} / \mathrm{m}^{3}$, revised prioritization cost is determined and shown as $5^{\text {th }}$ column of Table 8 . From $5^{\text {th }}$ column of Table 8 it can be observed that $T_{4}$ is still not cheaper. Based on step 7 , another revised pinch point is found at $(4750,1000)$ using the pivot point as $(8950,500)$. Prioritized cost is again determined for the pinch concentration of $1000 \mathrm{mg} / \mathrm{m}^{3}$ (see column 6 of Table 8). It can be observed that prioritized cost for $T_{4}$ is cheapest. Using equation (24), maximum utilizable point for $T_{4}$ can be determined as $10210 \mathrm{mg} / \mathrm{s}$. Using equation (25) and (26), revised $f_{t 1}$ and $f_{t 2}$ can be determined as $1.32 \mathrm{mg} / \mathrm{m}^{3}$ and $8.4 \mathrm{mg} / \mathrm{m}^{3}$, respectively. Using equation (27) flow treated in $T_{4}$ and $T_{2}$ can be determined as $7.08 \mathrm{mg} / \mathrm{m}^{3}$ and $1.32 \mathrm{mg} / \mathrm{m}^{3}$, respectively. Hence, the total operating cost for the given network is $16.044 \$ / \mathrm{s}$, which is identical with the mathematically solved result. Revised treatment line is shown in Figure 5. From figure 5 it can be observed that composite treatment line generated by treatment units $T_{4}$ and $T_{2}$ is able to remove $\Delta M_{T e f}$ of mass load. Flow from a higher concentration source to selected higher outlet concentration treatment unit is allocated up to their targeted flow to design an 
optimum network. The treatment network for this example is shown in Figure 6. Note that there may be several optimum allocation networks are possible. From Figure 6 it can be observed that treatment unit with least outlet concentration or only treatment units of least specific operating cost may not be in operation to achieve the optimum operating cost.

\section{Conclusions.}

A simple conceptual methodology based on pinch analysis for targeting multiple treatment units has been proposed in this paper. The methodology has been presented in graphical form (as the waste composite curve). Also, an algorithm has been demonstrated through variety of examples. The methodology is general enough to be applied to problems related to total waste (water, hydrogen as well as material) network. It has been observed that it is not necessary to maximize the usage of the treatment unit with the minimum specific cost (i.e., cost per unit effluent treatment flow). A prioritized cost for each treatment unit has been developed to select the appropriate treatment units that minimize operating cost. It may be noted that the proposed algorithm is applicable to treatment systems with fixed outlet concentration and without any limiting inlet concentration. Current research is directed toward developing appropriate algorithms which can take maximum allowable concentration limit for treatment units. The methodology can also be extended for determining optimum operating cost for treatment systems of fixed removal ratio. 


\section{Acknowledgement}

Authors are thankful to Department of Science and Technology (DST), India and National Research Foundation, South Africa for supporting the collaboration between IIT Bombay, India and University of Pretoria, South Africa under 'Indian/ South African Science and Technology Cooperation Programme'. Authors are also thankful to the anonymous reviewers for suggestions that improved the readability of the paper.

\section{References}

1. Linnhoff, B., Townsend, D.W., Boland, D., Hewitt, G.F., Thomas, B.E.A., Guy, A.R., Marsland, R.H. User guide on process integration for the efficient use of energy. The Institution of Chemical Engineers. Rugby, UK, 1982.

2. Smith, R. Chemical process design. McGraw-Hill, New York, 1995.

3. El-Halwagi M.M. Process integration. Elsevier, Amsterdam, 2006.

4. Takama, N., Kuriyama, T., Shiroko, K., Umeda, T. Optimal water allocation in petroleum refinery. Comput. Chem. Eng, 1980, 4, 251.

5. Wang, Y.P., Smith, R. Design of distributed effluent treatment systems. Chem. Eng. Sci. 1994, 49, 3127.

6. Kuo, W.C.J., Smith, R. Effluent treatment system design. Chem. Eng. Sci. 1997, 52, 4273.

7. Galan, B., Grossmann, I.E. Optimal design of distributed wastewater treatment networks. Ind. Eng. Chem. Res. 1998, 37, 4036. 
8. Hernández-Suáırez, R., Castellanos-Fernández, J., Zamora, J.M. Superstructure decomposition and parametric optimization approach for the synthesis of distributed wastewater treatment networks. Ind. Eng. Chem. Res. 2004, 43, 2175.

9. Alva-Argáez, A., Kokossis, A.C., Smith, R. Automated design of industrial water networks. American Institute of Chemical Engineering Annual Meeting Paper 13f, Miami, FL, 1998.

10. Alva-Argáez, A., Kokossis, A.C., Smith, R. Wastewater minimization of industrial systems using an integrated approach. Comput. Chem. Eng. 1998, 22,741-S744.

11. Freitas, I.S.F., Boaventura, R.A.R., Costa, C.A.V. Conceptual design of industrial wastewater treatment processes: a hierarchical approach procedure, in: Proceedings of the Second Conference on Process Integration, Modeling and Optimization for Energy savings and Pollution Reduction (PRESS'99), Budapest, Hungary, 1999.

12. Douglas, J.M. Conceptual design of chemical processes. McGraw-Hill, New York, 1988.

13. Statyukha, G., Kvitka, O., Dzhygyrey, I., Jezowski, J. A simple sequential approach for designing industrial wastewater treatment networks. J. Clean. Prod. 2008, 16, 215-224.

14. Tan, R.R., Ng, D.K.S., Foo, D.C.Y., Aviso, K.B. A superstructure model for the synthesis of single-contaminant water networks with partitioning regenerators. Process Saf. Environ. Protect. 2009, 87, 197-205.

15. Ng, D.K.S., Foo, D.C.Y., Tan, R.R. Automated targeting technique for single-impurity resource conservation networks. Part 2: Single-pass and partitioning waste-interception systems. Ind. Eng. Chem. Res. 2009, 48 (16), 7647-7661. 
16. Zhelev, T.K., Bhaw, N. Combined water-oxygen pinch analysis for better waste water treatment management. Waste Management 2000, 20, 665-670.

17. Kuo, W.C.J., Smith, R. Designing for the interactions between water use and effluent treatment. Trans. Inst. Chem. Eng. 1998, 76, 287.

18. Chang, C.-T., Li, B.-H. Improved optimization strategies for generating practical waterusage and -treatment network structures. Ind. Eng. Chem. Res. 2005, 44, 3607-3618.

19. Gunaratnam, M., Alva-Argaez, A., Kokossis, A., Kim, J.-K., Smith, R. Automated design of total water systems. Ind. Eng. Chem. Res. 2005, 44, 588-599.

20. Bandyopadhyay, S., Ghanekar, M.D., Pillai, H.K. Process water management. Ind. Eng. Chem. Res. 2006, 45, 5287-5297.

21. Ng, D.K.S., Foo, D.C.Y., Tan, R.R. Targeting for total water network. part 2.waste treatment targeting and interactions with water system elements. Ind. Eng. Chem. Res. 2007, 46, 9114-9125.

22. Ng, D.K.S., Foo, D.C.Y., Tan, R.R., Tan, Y.L. Ultimate flow rate targeting with regeneration placement. Chem. Eng. Res. Design 2007, 85, 1253-1267.

23. Bandyopadhyay, S., Cormos, C.C. Water management in process industries incorporating regeneration and recycle through single treatment unit. Ind. Eng. Chem. Res. 2008, 47, 1111-1119.

24. Bandyopadhyay, S. Targeting minimum waste treatment flow rate. Chemical Engineering Journal 2009, 152, 367-375.

25. Liu, Z.-H., Shi, J., Liu, Z.-Y. Design of wastewater treatment networks with single contaminant. Chemical Engineering Journal. 2012, 192, 315 - 325. 
26. Ahuja, R.K.; Magnanti, T.L.; Orlin, J.B. Network Flows: Theory, Algorithm, and Applications, Prentice-Hall, Englewood Cliffs, NJ, 1993.

27. Shenoy, U. V., Bandyopadhyay, S. Targeting for Multiple Resources. Industrial \& Engineering Chemistry Research 2007, 46, 3698-3708.

28. Das, A.K., Shenoy, U.V., Bandyopadhyay, S. Evolution of resource allocation networks. Ind. Eng. Chem. Res. 2009, 48(15), 7152-7167.

29. Parthasarathy, G., El-Halwagi, M.M. Optimum mass integration strategies for condensation and allocation of multi component VOCs. Chem. Eng. Sci. 2000, 55, 881895. 


$$
\begin{aligned}
& \text { Nomenclature } \\
& C \quad=\text { contaminant concentration }(\mathrm{ppm}) \\
& C_{e} \quad=\text { environmental discharge limit }(\mathrm{ppm}) \\
& C_{e}^{\prime} \quad=\text { aggregate discharge limit from treatment plant }(\mathrm{ppm}) \\
& C_{f k}=\text { concentration for which } f_{T k} \text { is maximum (ppm) } \\
& C_{p k} \quad=\text { pinch concentration while targeting } f_{T k}(\mathrm{ppm}) \\
& C_{p k r} \quad=\text { revised pinch concentration when } T_{k} \text { is not cheapest w.r.t. } C_{p k}(\mathrm{ppm}) \\
& M_{p k} \quad=\text { contaminant load corresponding to pinch concentration } C_{p k}(\mathrm{~kg}) \\
& M_{p k r} \quad=\text { contaminant load corresponding to revised pinch concentration } C_{p k r}(\mathrm{~kg}) \\
& C_{\text {out }} \quad=\text { outlet concentration of treatment unit }(\mathrm{ppm}) \\
& \left.C_{\text {out }}=\text { outlet concentration of } i^{\text {th }} \text { treatment unit ( } \mathrm{ppm}\right) \\
& C_{p} \quad=\text { pinch concentration }(\mathrm{ppm}) \\
& C_{p j} \quad=\text { pinch concentration due to } j^{\text {th }} \text { treatment unit (ppm) } \\
& C_{s i} \quad=\text { concentration of } i^{\text {th }} \text { source }(\mathrm{ppm}) \\
& C_{k} \quad=k^{\text {th }} \text { concentration level }(\mathrm{ppm}) \\
& \text { Cum = cumulative } \\
& f \quad=\text { flow variable }(\mathrm{kg} / \mathrm{s}) \\
& F \quad=\text { fix flow }(\mathrm{kg} / \mathrm{s}) \\
& F_{l} \quad=\text { flow at the concentration level } C_{l}(\mathrm{~kg} / \mathrm{s}) \\
& F_{s i} \quad=\text { flow produced by the } i^{\text {th }} \text { source }(\mathrm{kg} / \mathrm{s}) \\
& f_{T k} \quad=\text { effluent treatment flow for } k^{\text {th }} \text { treatment unit }(\mathrm{kg} / \mathrm{s}) \\
& f_{t k} \quad=\text { effluent treatment flow for } k^{\text {th }} \text { targeted treatment unit }(\mathrm{kg} / \mathrm{s}) \\
& F_{T k} \quad=\text { flow to be treated in } k^{\text {th }} \text { targeted treatment unit }(\mathrm{kg} / \mathrm{s})
\end{aligned}
$$




$$
\begin{aligned}
& f_{i j}=\text { flow transferred from } i^{\text {th }} \text { source to } j^{\text {th }} \text { treatment unit }(\mathrm{kg} / \mathrm{s}) \\
& f_{i b} \quad=\text { flow by-passed from } i^{\text {th }} \text { source }(\mathrm{kg} / \mathrm{s}) \\
& f_{T i j}=\text { flow transferred from } i^{\text {th }} \text { treatment unit to } j^{\text {th }} \text { treatment unit }(\mathrm{kg} / \mathrm{s}) \\
& f_{\text {Tie }}=\text { flow transferred from } i^{\text {th }} \text { treatment unit to environment }(\mathrm{kg} / \mathrm{s}) \\
& f_{T} \quad=\text { treatment flow requirement }(\mathrm{kg} / \mathrm{s}) \\
& f_{T j, k} \quad=\text { flow corresponding to concentration } C_{k} \text { due to treatment unit } T_{j}(\mathrm{~kg} / \mathrm{s}) \\
& f_{k} \quad=\text { flow corresponding to concentration } C_{k}(\mathrm{~kg} / \mathrm{s}) \\
& \Delta f_{T, k} \quad=\text { change in treatment flow requirement } k^{\text {th }} \text { concentration } \\
& M \quad=\text { cumulative contaminant load }(\mathrm{kg}) \\
& M_{k} \quad=\text { cumulative contaminant load at } k^{\text {th }} \text { concentration level }(\mathrm{kg}) \\
& M_{T} \quad=\text { total contaminant load }(\mathrm{kg}) \\
& M_{T i} \quad=\text { contaminant load removed by } T_{i}(\mathrm{~kg}) \\
& M_{f k} \quad=\text { contaminant load for which } f_{T k} \text { is maximum }(\mathrm{kg}) \\
& M_{p k} \quad=\text { contaminant load corresponding to pinch concentration } C_{p k}(\mathrm{~kg}) \\
& M_{p k r} \quad=\text { contaminant load corresponding to revised pinch concentration } C_{p k r}(\mathrm{~kg}) \\
& \Delta M_{T e f} \quad=\text { effluent contaminant load to be treated }(\mathrm{kg}) \\
& \Delta M_{s} \quad=\text { effluent contaminant load can be discharged without treated }(\mathrm{kg}) \\
& n \quad=\text { Number of treatment units } \\
& N W \quad=\text { Number of waste generating sources } \\
& P \quad=\text { pinch point } \\
& S \quad=\text { source } \\
& \text { Ti } \quad=i^{\text {th }} \text { treatment unit } \\
& U_{T i} \quad=\text { specific cost of ith treatment unit }(\$ / \mathrm{kg})
\end{aligned}
$$




\section{List of Abbreviations}

LP = linear programming

ppm $\quad=$ parts per million

$\mathrm{SCC}=$ source composite curve

WAN = water allocation network

RPC $=$ revised prioritized cost

VOCs = volatile organic compounds

\section{Greek letters}

$\begin{array}{ll}\Delta & =\text { difference } \\ \delta & =\text { change } \\ \in & =\text { belongs to } \\ \forall & =\text { for each } \\ \ni & =\text { such that } \\ \Psi & =\text { operating cost }\end{array}$

\section{Subscript}

$\mathrm{d}=$ demand

$\min =$ minimum

$\mathrm{s} \quad=$ source

$\mathrm{r}=$ revised

\section{Indices}

$i, j, k, l$ 


\section{List of Figure Captions}

Figure 1: The schematic of the water treatment network.

Figure 2: General waste composite curve, treatment line and treatment pinch for single treatment unit.

Figure 3: General waste composite curve and composite line for prioritizing treatment units.

Figure 4: Waste composite curve and composite line for example 1

Figure 5: Waste composite curve and composite line for example 2.

Figure 6: Treatment network with minimum operating cost of example 2. 


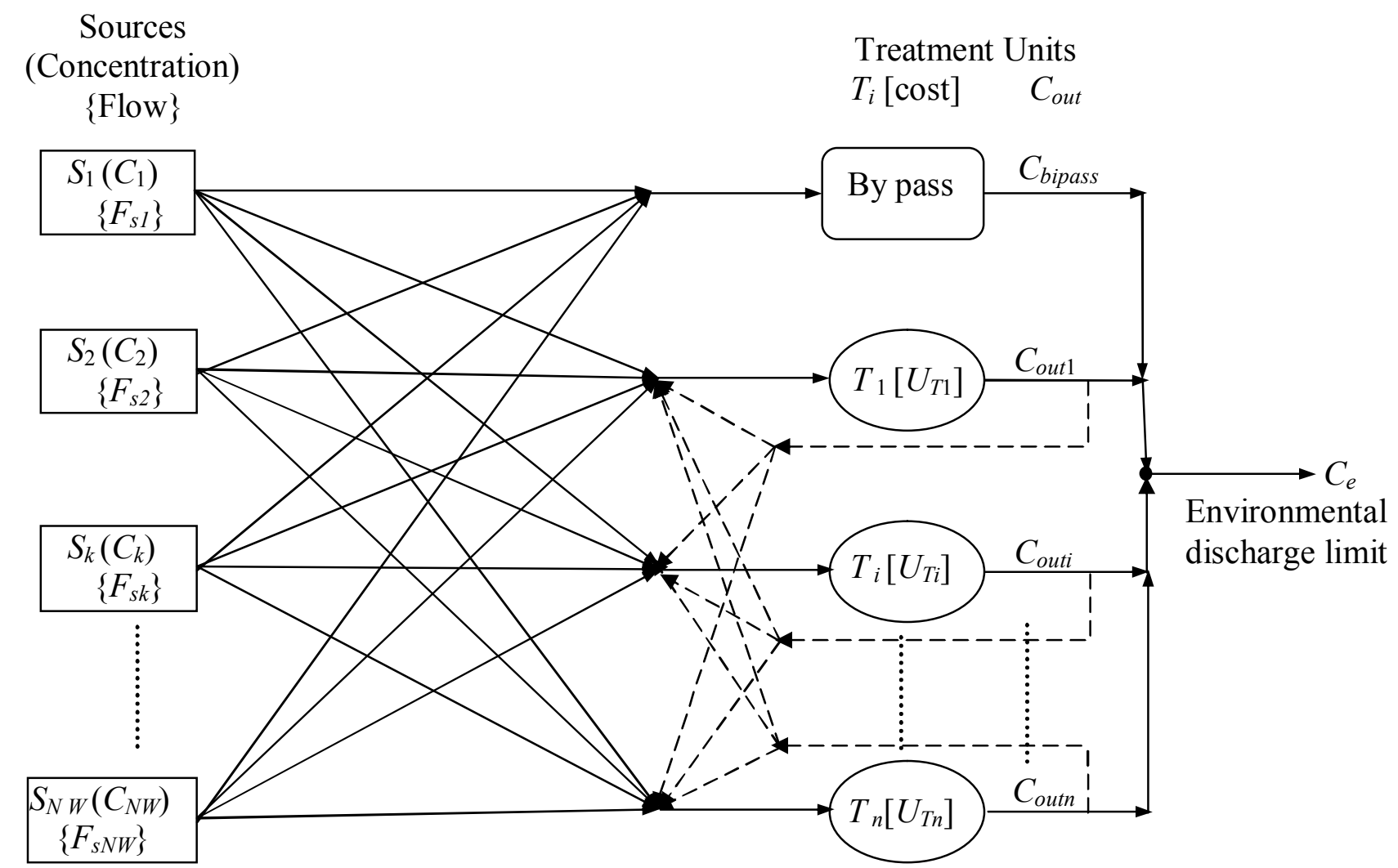

Figure 1: The schematic of the water treatment network. 


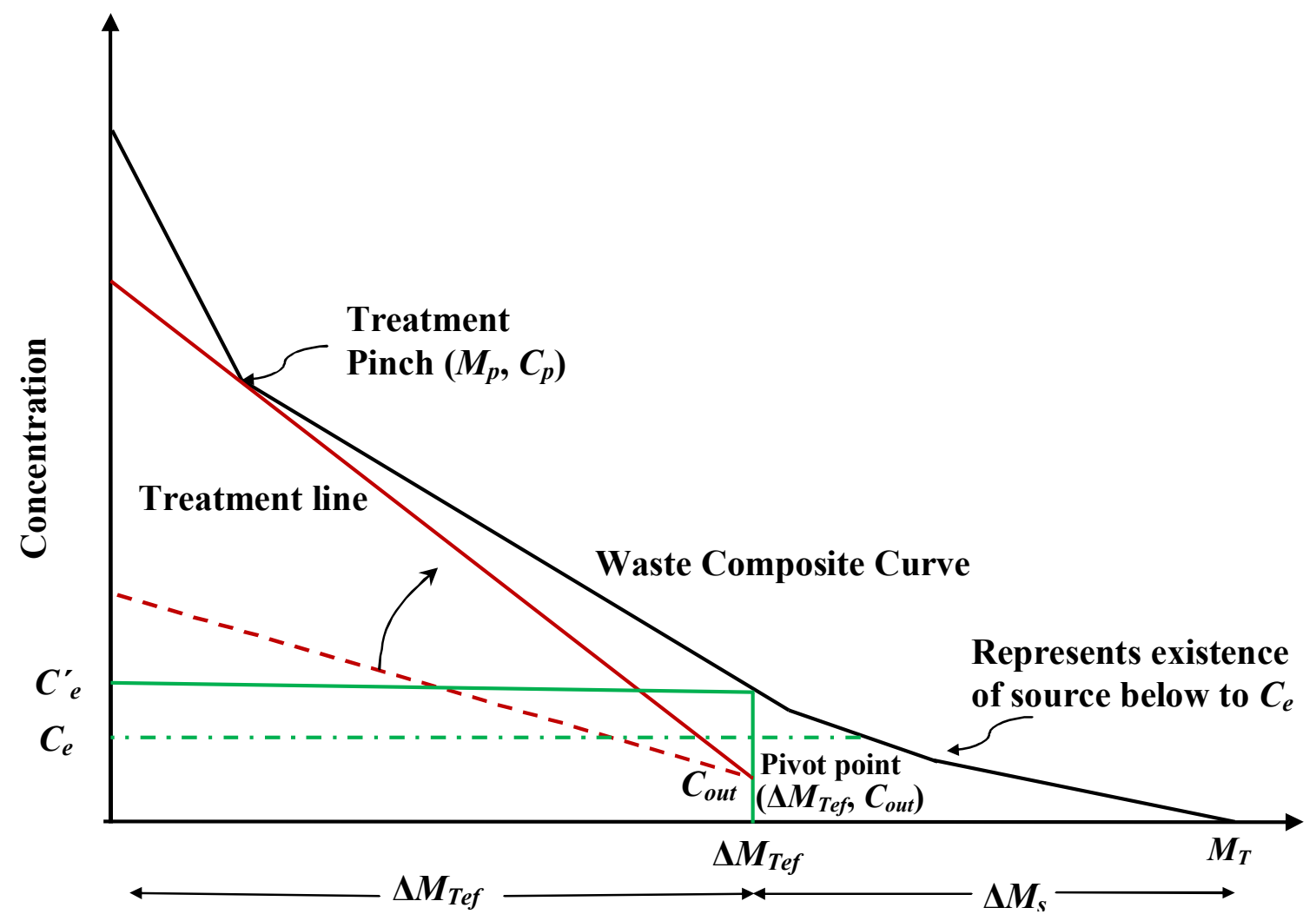

Cumulative contaminant load

Figure 2: General waste composite curve, treatment line and treatment pinch for single treatment unit. 


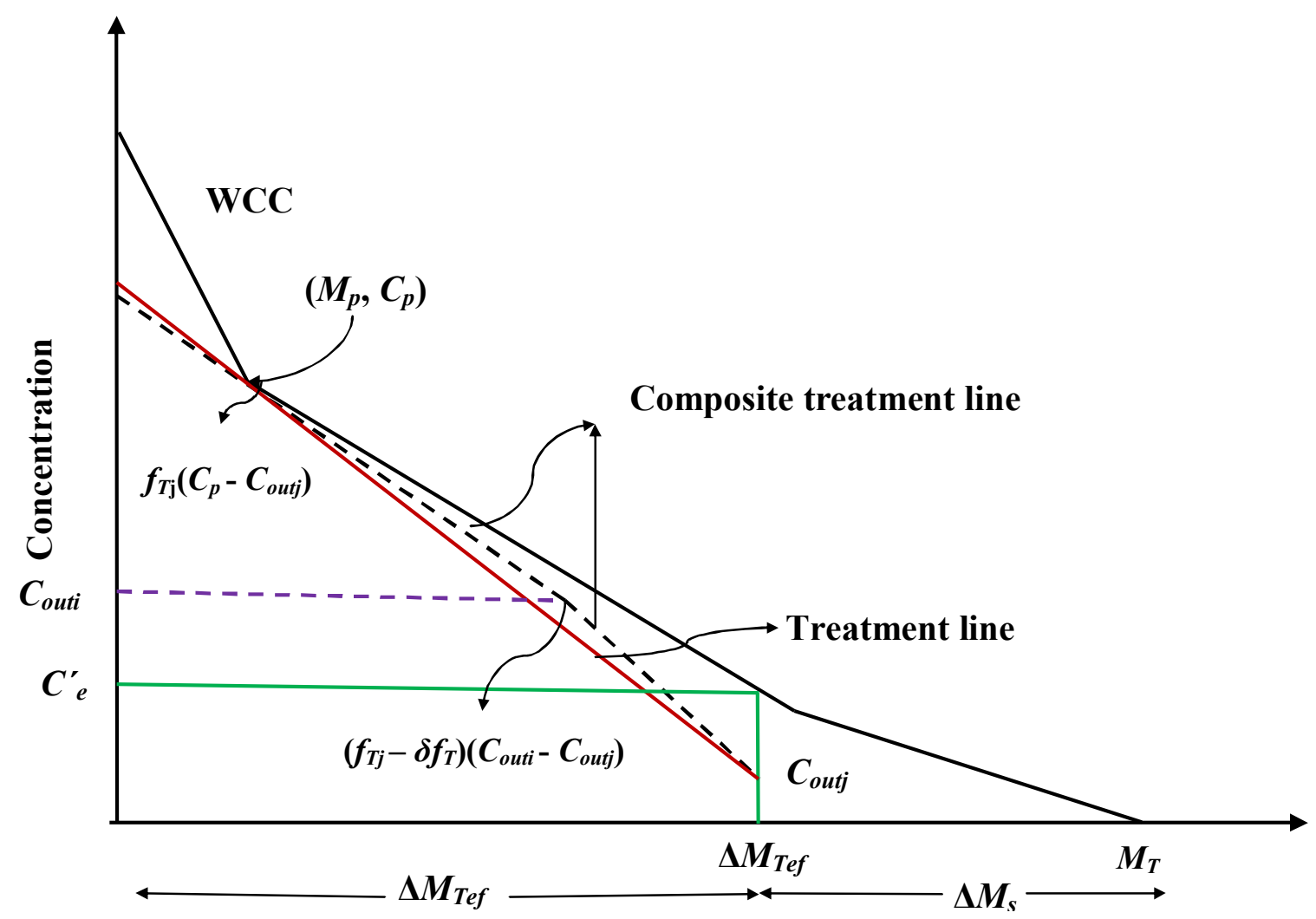

\section{Cumulative contaminant load}

Figure 3: General waste composite curve and composite line for prioritizing treatment units. 


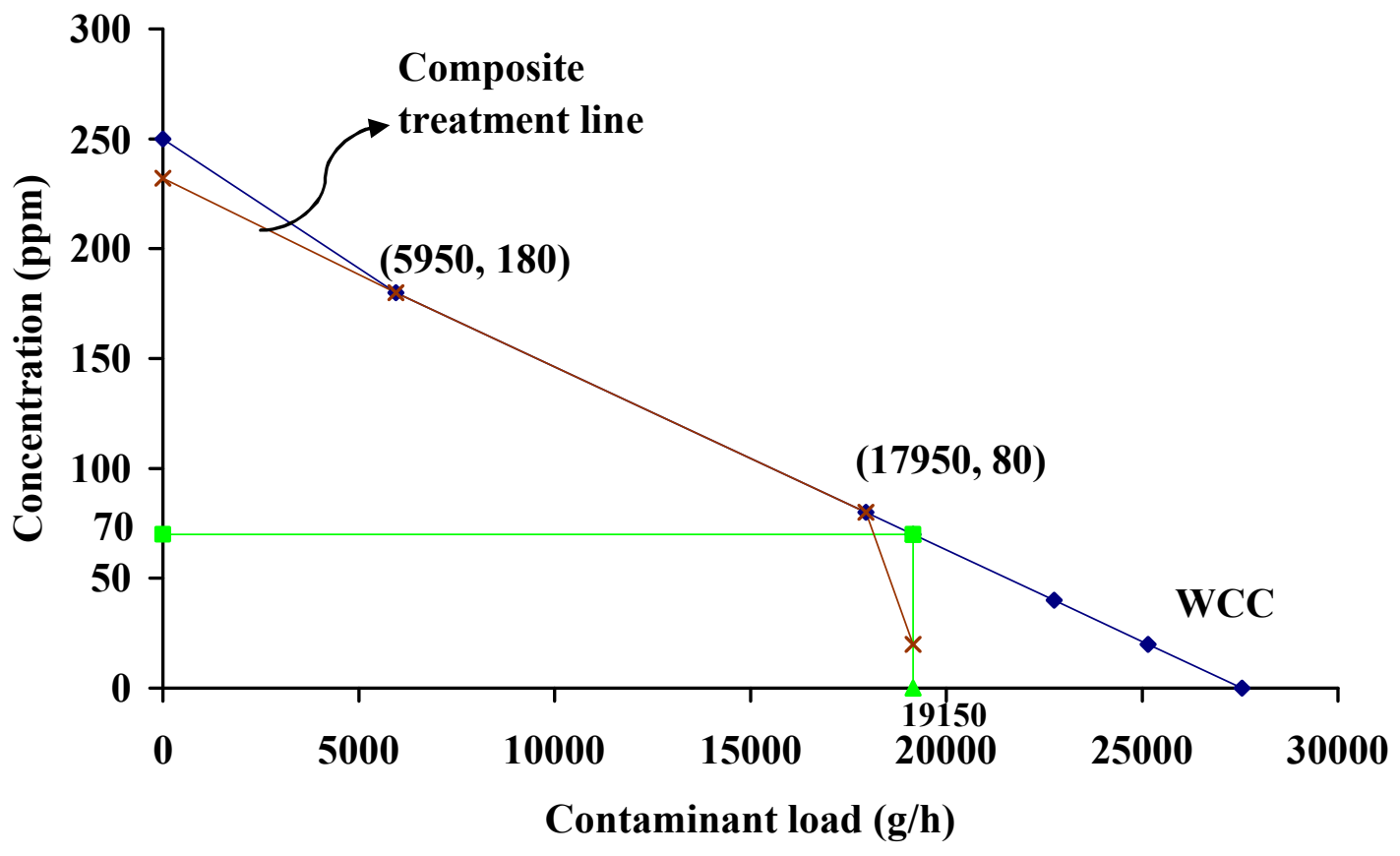

Figure 4: Waste composite curve and composite line for example 1.

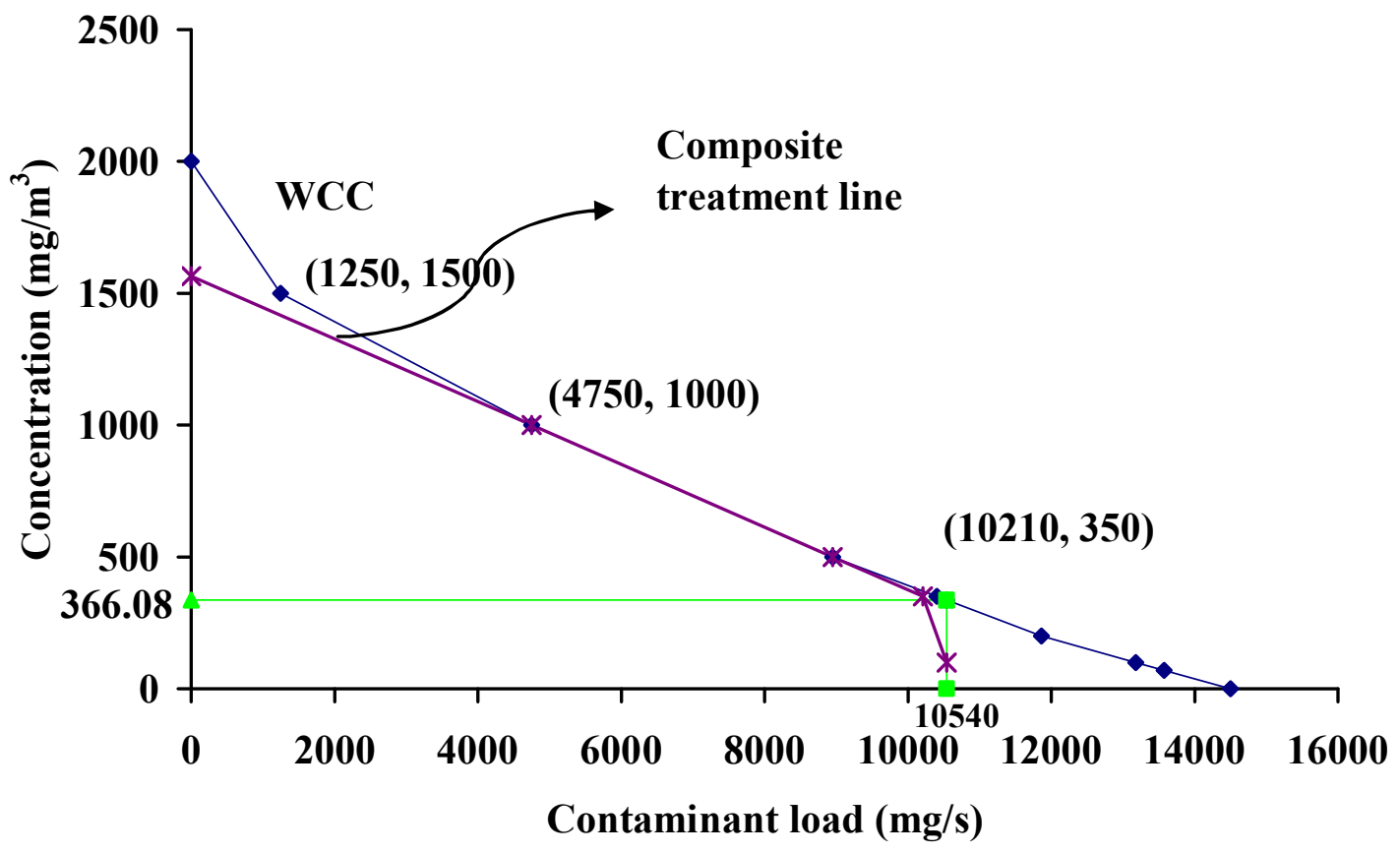

Figure 5: Waste composite curve and composite line for example 2. 
Sources

(Concentration, $\mathrm{mg} / \mathrm{m}^{3}$ )

$\left\{\right.$ Flow, $\mathrm{m}^{3} / \mathrm{s}$ \}
Treatment Units

$T_{i} \quad C_{\text {out }}$

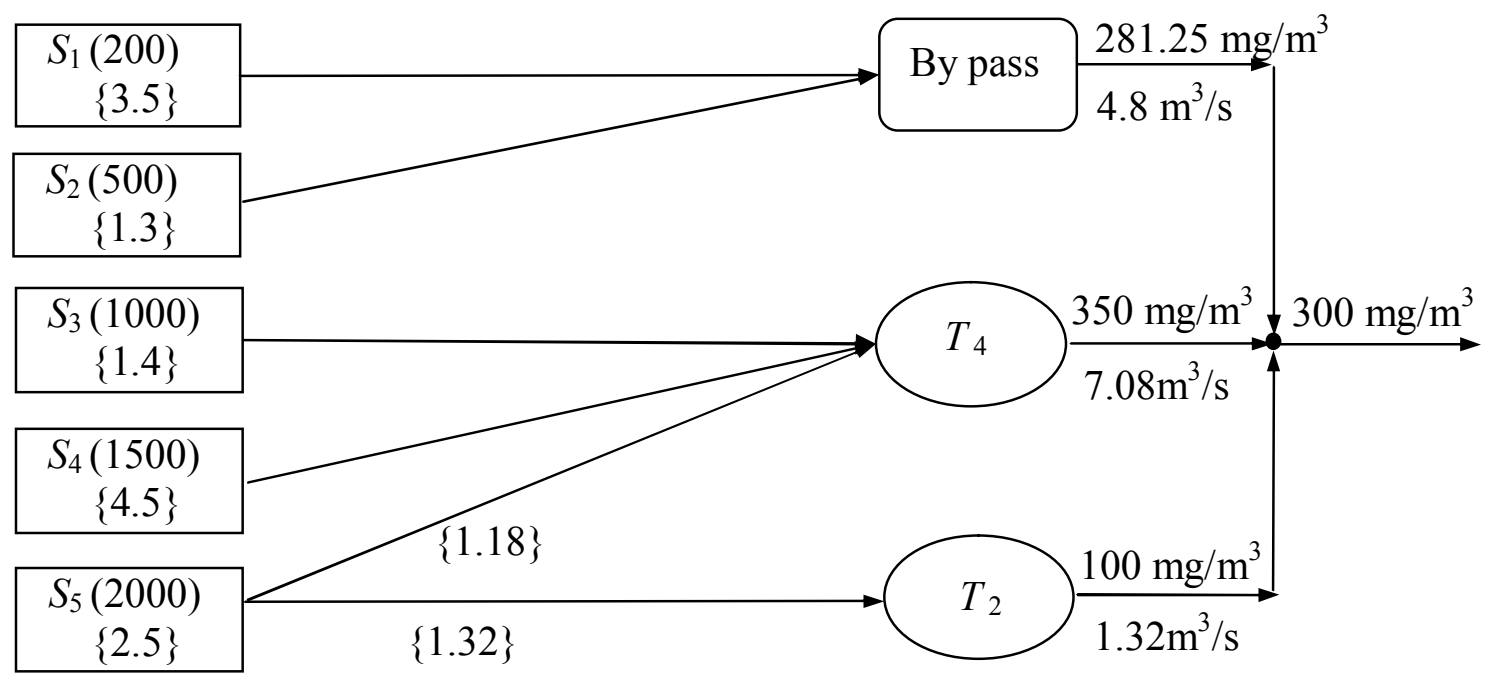

Figure 6: Treatment network with minimum operating cost of example 2. 


\section{List of Table Captions}

Table 1: Remarks on reordering of prioritized cost due to change in treatment pinch

Table 2: Data for example 1

Table 3: Targeting for effluent flow rate with optimized operating cost for example 1

Table 4: Prioritization of treatment units of example 1

Table 5: Matching matrix representation of total water network for example 1

Table 6: Data for example 2.

Table 7: Targeting for effluent flow rate with optimized operating cost for example 2

Table 8: Prioritization of treatment units of example 2 
Table 1: Remarks on reordering of prioritized cost due to change in treatment pinch

\begin{tabular}{cccc}
\hline Relation of & Relation of & Remark & Equation used \\
treatment units & costs & & \\
\hline$C_{\text {outk }}>C_{\text {outi }}, \forall k$ & $U_{T k}>U_{T i} \forall k$ & $P C\left(T_{i}\right)<P C\left(T_{K}\right), R P C\left(T_{i}\right)<R P C\left(T_{k}\right)$ & Equation (18) \\
& $U_{T k}<U_{T i} \forall k$ & $P C\left(T_{i}\right)<P C\left(T_{K}\right), R P C\left(T_{i}\right)<R P C\left(T_{k}\right)$ & Equation (20) \\
$C_{\text {outk }}<C_{\text {outi }}, \forall k$ & $U_{T k}>U_{T i} \forall k$ & $P C\left(T_{i}\right)<P C\left(T_{K}\right)$, cannot say for RPC & Equation (20) \\
& $U_{T k}<U_{T i} \forall k$ & Not possible, Equation (18) is violated & Equation (18) \\
\hline
\end{tabular}


Table 2: Data for example 1

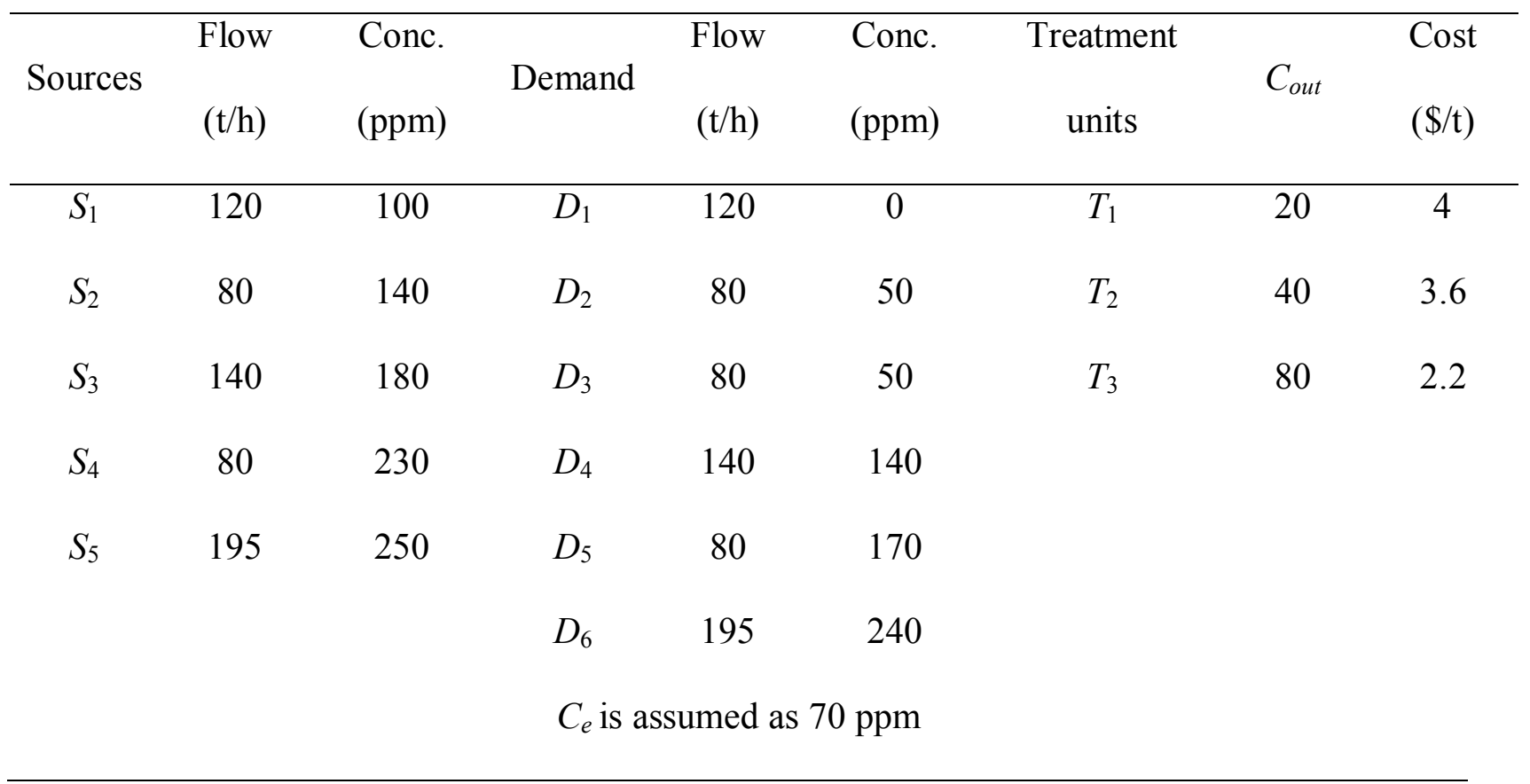


Table 3: Targeting for effluent flow rate with optimized operating cost for example 1

\begin{tabular}{|c|c|c|c|c|}
\hline $\begin{array}{l}\text { Concentration } \\
\text { (ppm) }\end{array}$ & $\begin{array}{l}\text { Cum contaminant } \\
\text { load }(\mathrm{g} / \mathrm{h})\end{array}$ & $\begin{array}{l}\text { Treatment } \\
\text { flow w.r.t. } T_{1} \\
\text { (20 ppm) }\end{array}$ & $\begin{array}{c}\text { Treatment } \\
\text { flow w.r.t. } T_{2} \\
\text { (40 ppm) }\end{array}$ & $\begin{array}{l}\text { Treatment } \\
\text { flow w.r.t } \\
\left(M_{p}, C_{p}\right) \text { of } \\
(5950,180)\end{array}$ \\
\hline 250 & 0 & 83.26 & 91.19 & 120 \\
\hline 180 & 5950 & 82.5 & 94.28 & \\
\hline 80 & 17950 & & & \\
\hline $70\left(C_{e}^{\prime}\right)$ & $19150\left(\Delta M_{t e f}\right)$ & & & \\
\hline 40 & 22750 & & & \\
\hline 20 & 25150 & & & \\
\hline 0 & 27550 & & & \\
\hline
\end{tabular}


Table 4: Prioritization of treatment units of example 1

\begin{tabular}{ccccc}
\hline Treatment & $C_{\text {out }}$ & Cost & Prioritized cost w.r.t & Prioritized cost w.r.t \\
units & $(\mathrm{ppm})$ & $(\$ / \mathrm{t})$ & $C_{p}=250 \mathrm{ppm}$ & $C_{p}=180 \mathrm{ppm}$ \\
\hline$T_{1}$ & 20 & 4 & 0.017391304 & 0.025 \\
$T_{2}$ & 40 & 3.6 & 0.017142857 & 0.02571 \\
$T_{3}$ & 80 & 2.2 & 0.012941176 & 0.022 \\
\hline
\end{tabular}


Table 5: Matching matrix representation of total water network for example 1

\begin{tabular}{|c|c|c|c|c|c|c|c|c|c|c|}
\hline \multicolumn{2}{|l|}{$F \mathrm{t} / \mathrm{h}$} & 120 & 80 & 80 & 140 & 80 & 195 & 20 & 100 & 120 \\
\hline \multicolumn{2}{|c|}{$C \mathrm{ppm}$} & $\{0\}$ & $\{50\}$ & $\{50\}$ & $\{140\}$ & $\{170\}$ & $\{240\}$ & --- & --- & $\{70\}$ \\
\hline & & $D_{1}$ & $D_{2}$ & $D_{3}$ & $D_{4}$ & $D_{5}$ & $D_{6}$ & $T_{1 \text { in }}$ & $T_{3 i n}$ & $\mathrm{~W}$ \\
\hline $120\{100\}$ & $\overline{S_{1}}$ & & 40 & 40 & 30 & 10 & & & & \\
\hline $80\{140\}$ & $S_{2}$ & & & & 80 & & & & & \\
\hline $140\{180\}$ & $S_{3}$ & & & & 30 & 70 & 5 & 20 & 15 & \\
\hline $80\{230\}$ & $S_{4}$ & & & & & & 80 & & & \\
\hline $195\{250\}$ & $S_{5}$ & & & & & & 110 & & 85 & \\
\hline $200\{0\}$ & $F_{r}$ & 120 & 40 & 40 & & & & & & \\
\hline $20\{20\}$ & $T_{1 \text { lout }}$ & & & & & & & & & 20 \\
\hline $100\{80\}$ & $T_{3 o u t}$ & & & & & & & & & 100 \\
\hline
\end{tabular}


Table 6: Data for example 2.

\begin{tabular}{|c|c|c|c|c|c|}
\hline Sources & $\begin{array}{l}\text { Flow } \\
\left(\mathrm{m}^{3} / \mathrm{s}\right)\end{array}$ & $\begin{array}{l}\text { Concentration } \\
\qquad\left(\mathrm{mg} / \mathrm{m}^{3}\right)\end{array}$ & Treatment units & $\begin{array}{c}C_{\text {out }} \\
\left(\mathrm{mg} / \mathrm{m}^{3}\right)\end{array}$ & $\begin{array}{l}\text { Cost } \\
\left(\$ / \mathrm{m}^{3}\right)\end{array}$ \\
\hline $\bar{S}$ & 3.5 & 200 & $T_{1}$ & 70 & 3 \\
\hline$S_{2}$ & 1.3 & 500 & $T_{2}$ & 100 & 2.5 \\
\hline$S_{3}$ & 1.4 & 1000 & $T_{3}$ & 200 & 2.4 \\
\hline$S_{4}$ & 4.5 & 1500 & $T_{4}$ & 350 & 1.8 \\
\hline$S_{5}$ & 2.5 & 2000 & $T_{5}$ & 500 & 1.5 \\
\hline \multicolumn{6}{|c|}{$C_{e}$ is assumed as $300 \mathrm{mg} / \mathrm{m}^{3}$} \\
\hline
\end{tabular}


Table 7: Targeting for effluent flow rate with optimized operating cost for example 2

\begin{tabular}{|c|c|c|c|c|}
\hline $\begin{array}{l}\text { Concentration } \\
\qquad\left(\mathrm{mg} / \mathrm{m}^{3}\right)\end{array}$ & $\begin{array}{l}\text { Cum contaminant } \\
\text { load }(\mathrm{mg} / \mathrm{s})\end{array}$ & $\begin{array}{c}\text { Treatment } \\
\text { flow w.r.t. } T_{1} \\
\left(70 \mathrm{mg} / \mathrm{m}^{3}\right)\end{array}$ & $\begin{array}{l}\text { Treatment } \\
\text { flow w.r.t. } T_{2} \\
\left(100 \mathrm{mg} / \mathrm{m}^{3}\right)\end{array}$ & $\begin{array}{c}\text { Treatment } \\
\text { flow w.r.t. } \\
T_{4} \\
\left(350 \mathrm{mg} / \mathrm{m}^{3}\right)\end{array}$ \\
\hline 2000 & 0 & 5.46 & & 6.306061 \\
\hline 1500 & 1250 & 6.50 & & 7.96087 \\
\hline 1000 & 4750 & 6.23 & & 8.7 \\
\hline 500 & 8950 & 3.70 & & 9.7 \\
\hline 350 & 10405 & 0.48 & 0.54 & \\
\hline $336.08\left(C_{e}^{\prime}\right)$ & $10540\left(\Delta M_{t e f}\right)$ & 0.00 & 0 & \\
\hline 200 & 11860 & & & \\
\hline 100 & 13180 & & & \\
\hline 70 & 13576 & & & \\
\hline 0 & 14500 & & & \\
\hline
\end{tabular}


Table 8: Prioritization of treatment units of example 2

\begin{tabular}{cccccc}
\hline Treatment & $\begin{array}{c}C_{\text {out }} \\
\text { units }\end{array}$ & $\begin{array}{c}\text { Cost } \\
\left(\mathrm{mg} / \mathrm{m}^{3}\right)\end{array}$ & $\begin{array}{c}\text { Prioritized cost w.r.t } \\
\left(\$ \mathrm{~m}^{3}\right)\end{array}$ & $\begin{array}{c}C_{p}=1500 \mathrm{mg} / \mathrm{m}^{3} \\
C_{p}=500 \mathrm{mg} / \mathrm{m}^{3}\end{array}$ & $\begin{array}{c}\text { Prioritized cost w.r.t } \\
C_{p}=1000 \mathrm{mg} / \mathrm{m}^{3}\end{array}$ \\
\hline$T_{1}$ & 70 & 3 & 0.0021 & 0.00698 & 0.00323 \\
$T_{2}$ & 100 & 2.5 & 0.00178 & 0.00625 & 0.00278 \\
$T_{3}$ & 200 & 2.4 & 0.00184 & 0.008 & 0.003 \\
$T_{4}$ & 350 & 1.8 & 0.0016 & 0.012 & 0.00277 \\
$T_{5}$ & 500 & 1.5 & 0.0015 & indefinite & 0.003 \\
\hline
\end{tabular}

